\title{
LETTER
}

\section{Severity of community-acquired pneumonia treated with low-dose adjunctive corticosteroid}

\author{
Katsunaka Mikami', Masaru Suzuki2,*, Hiroshi Kitagawa ${ }^{3}$, Masaki Kawakami², Nobuaki Hirota', Ayako Shimbara-Mikami ${ }^{5}$ \\ and Yoshio Sakamoto
}

See related research by Fernández-Serrano et al., http://ccforum.com/content/15/2/R96

We read with interest the report of the randomized double-blind controlled trial by Fernández-Serrano and colleagues [1] suggesting that the administration of methyl-prednisolone (MPDN) with ceftriaxone plus levofloxacin improves clinical variables in communityacquired pneumonia (CAP). Compared with randomly controlled studies in which patients benefited from corticosteroid treatment [2-4], all patients of this study received the same antibiotics. It is striking that this study has overcome the problem that choice and dose of antibiotics may influence results.

However, several points should be discussed. First, it would be better to consider the severity of CAP because adjunctive corticosteroid treatment should not be routinely administrated to patients with any severity of CAP. In fact, the results of our study suggest that corticosteroid treatment lacks efficacy in cases of mild to moderate CAP [3]. Although additional subgroup analysis may lead to similar results to those of our study because more than $50 \%$ of patients in both studies had a pneumonia severity index [5] rating of IV or V [1,3], the target population for corticosteroid treatment should be precisely identified. Moreover, although the authors administrated $620 \mathrm{mg}$ MPDN per patient, we [3] and Meijvis and colleagues [4] showed a beneficial effect with lower doses of corticosteroids over shorter periods. The authors should consider lower doses and shorter periods of MPDN treatment in a future study.

Although this study could clearly provide significantly beneficial evidence of the value of MPDN treatment, the severity of pneumonia should be addressed because of the potential risk associated with corticosteroid treatment.

\section{Authors' response}

Jordi Dorca, Silvia Fernández-Serrano and Frederic Manresa

We thank Dr Suzuki and colleagues for their comments. Our study [1] aimed to demonstrate the potential effect of corticosteroid adjunctive therapy on the clinical outcome of severe CAP, so inclusion criteria included extensive radiological consolidation completely affecting at least two lobes, as well as a oxygen partial pressure/ inspired oxygen fraction ratio $\left(\mathrm{pO}_{2} / \mathrm{FiO}_{2}\right)<300$. This is how we concluded that adjunctive MPDN improves respiratory failure and accelerates the timing of clinical resolution of severe CAP. In our opinion, only this population could benefit from steroid administration.

*Correspondence: masaruszk@aol.com

${ }^{2}$ Department of Internal Medicine, Kanto Central Hospital 6-25-1 Kamiyoga,

Setagaya-ku, Tokyo 158-8531, Japan

Full list of author information is available at the end of the article
We elected to give higher doses of corticosteroids than in other studies $[3,4,6]$ to increase the chance of showing a positive effect. However, we cannot exclude that a lower dosage may have a beneficial effect. Having said that, it is also possible that the improvement may be dosedependent; therefore, once evidence of a benefit has been definitively shown in larger series, prospective controlled studies comparing different doses and schedules will be needed.

\section{Abbreviations}

CAP, community-acquired pneumonia; MPDN, methyl-prednisolone.

\section{Competing interests}

The authors declare that they have no competing interests.

\section{Author details}

'Department of Psychiatry, Tokai University School of Medicine, 143 Shimokasuya, Isehara, Kanagawa 259-1193, Japan. ${ }^{2}$ Department of Internal Medicine, Kanto Central Hospital 6-25-1 Kamiyoga, Setagaya-ku, Tokyo 1588531, Japan. ${ }^{3}$ Medical Oncology Branch, Center for Cancer Research, National Cancer Institute, Bethesda, MD 20892, USA. ${ }^{4}$ Meakins-Christie Laboratories, 
Department of Medicine, McGill University, Montréal, Quebec, Canada. ${ }^{5}$ Department of Clinical Pharmacology, Tokai University School of Medicine, 143 Shimokasuya, Isehara, Kanagawa 259-1193, Japan.

\section{Published: 8 November 2011}

\section{References}

1. Fernández-Serrano S, Dorca J, Garcia-Vidal C, Fernández-Sabé N, Carratalà J, Fernández-Agüera A, Corominas M, Padrones S, Gudiol F, Manresa F: Effect of corticosteroids on the clinical course of community-acquired pneumonia: a randomized controlled trial. Crit Care 2011, 15:R96.

2. Confalonieri M, Urbino R, Potena A, Piattella M, Parigi P, Puccio G, Della Porta R, Giorgio C, Blasi F, Umberger R, Meduri GU: Hydrocortisone infusion for severe community-acquired pneumonia: a preliminary randomized study. Am J Respir Crit Care Med 2005, 171:242-248.

3. Mikami K, Suzuki M, Kitagawa H, Kawakami M, Hirota N, Yamaguchi H, Narumoto O, Kichikawa Y, Kawai M, Tashimo H, Arai H, Horiuchi T, Sakamoto Y: Efficacy of corticosteroids in the treatment of community-acquired pneumonia requiring hospitalization. Lung 2007, 185:249-255.
4. Meijvis SC, Hardeman $H$, Remmelts $H H$, Heijligenberg R, Rijkers GT, van Velzen-Blad H, Voorn GP, van de Garde EM, Endeman H, Grutters JC, Bos WJ, Biesma DH: Dexamethasone and length of hospital stay in patients with community-acquired pneumonia: a randomised, double-blind, placebocontrolled trial. Lancet 2011, 377:2023-2030.

5. Fine MJ, Auble TE, Yealy DM, Hanusa BH, Weissfeld LA,Singer DE, Coley CM, Marrie TJ, Kapoor WN: A prediction rule to identify low-risk patients with communityacquired pneumonia. N Engl J Med 1997, 336:243-250.

6. Snijders D, Daniels JMA, de Graaff CS, van der WerfTS, Boersma WG: Efficacy of corticosteroids in community-acquired pneumonia: a randomized double-blinded clinical trial. Am J Respir Crit Care Med 2010, 181:975-982.

\section{doi:10.1186/cc10500}

Cite this article as: Mikami K, et al:: Severity of community-acquired pneumonia treated with low-dose adjunctive corticosteroid. Critical Care 2011, 15:451 